\title{
LA ENFERMEDAD DE LAS GENTES DEL MAR A TRAVÉS DE LA HISTORIA DEL ESPAÑOL: REVISIÓN DIACRÓNICA DE ESCORBUTO Y SUS SINÓNIMOS
}

\author{
Itziar Molina Sangüesa \\ Universidad de Salamanca \\ Email: itziarmolina@usal.es \\ ORCID iD: https://orcid.org/0000-0002-5520-3783
}

Recibido: 9 marzo 2020; Aceptado: 26 junio 2020

Cómo citar este artículo/Citation: Molina Sangüesa, Itziar (2021) "La enfermedad de las gentes del mar a través de la historia del español: revisión diacrónica de escorbuto y sus sinónimos", Asclepio, 73(1): p339. https://doi.org/10.3989/asclepio.2021.05

RESUMEN: En este trabajo se estudia la terminología que, en mayor o menor medida y durante más de cuatro siglos, se ha empleado en lengua española para referirse a la que se considera, históricamente, como la enfermedad de las gentes del mar por excelencia: el escorbuto (y algunas de sus variantes, como el escorbuto petequial, el muriático, el pedregoso, etc.). Asimismo, se constata la multiplicidad denominativa que este término desencadena para dar nombre a un tipo de enfermedad avitaminosa caracterizada por el déficit de vitamina C en el organismo (a saber: los vocablos berbén, loanda, mal de loanda, mal del gusanillo, peste del mar, escelotirbe, estomacace, gingibraquio, gingipedio y pequitirbo). Para ello, se analiza y se expone la documentación que tanto las bibliotecas como hemerotecas digitales, los bancos de datos de referencia del español y los repertorios lexicográficos hispánicos ofrecen sobre esta selección léxica.

PALABRAS CLAVE: Etimología; Sinonimia; Lexicografía diacrónica; Historia de la medicina; Léxico médico; Enfermedades avitaminosas.

\section{THE DISEASE OF THE PEOPLE OF THE SEA THROUGH THE HISTORY OF THE SPANISH LANGUAGE: DIACHRONIC REVIEW OF ESCORBUTO AND ITS SYNONYMS}

\begin{abstract}
In this paper we study the terminology that, for more than four centuries, has been used in the Spanish language to name what is considered, historically, as the disease of the sea people par excellence: the escorbuto (and its different variants, such as escorbuto petequial, muriático, aplomado, pedregoso, etc.). Likewise, it is verified the denominative multiplicity that this term triggers to give name to a type of avitamin disease, characterized by the deficit of vitamin C in the organism (that is, the words berbén, loanda, mal de loanda, mal del gusanillo, peste del mar, escelotirbe, estomacace, gingibraquio, gingipedio and pequitirbo). To do this, the documentation that digital libraries and lexicographic repertoires feature for this lexical selection is analyzed and offered.
\end{abstract}

KEY WORDS: Etymology; Synonymy; Diachronic Lexicography; History of Medicine; Medical Lexicon; Avitaminous Diseases. 


\section{PRESENTACIÓN}

En las siguientes páginas se analiza la terminología que -en mayor o menor medida- se ha empleado y divulgado en lengua española, durante más de cuatro centurias, para aludir a la que se considera, históricamente, como la enfermedad de las gentes del mar por excelencia: el escorbuto (y algunas de sus presuntas variantes o manifestaciones, como el escorbuto petequial, el muriático, el pedregoso, etc.). A este respecto, se constata la multiplicidad denominativa que este vocablo experimenta para dar nombre a un tipo de enfermedad avitaminosa caracterizada por el déficit de vitamina $\mathrm{C}$ en el organismo (algunos de sus sinónimos son: berbén, loanda, mal de loanda, mal del gusanillo, peste del mar, escelotirbe, estomacace, gingibraquio, gingipedio y pequitirbo). Para ello, se analiza con profusión y se expone la documentación que para esta decena de términos nos ofrecen las bibliotecas y hemerotecas digitales ${ }^{1}$, los bancos de datos de referencia del español ${ }^{2}$, así como repertorios lexicográficos de especialidad en materia médica, por un lado, y los de lengua general ${ }^{3}$, por otro.

\section{SOBRE LA ENFERMEDAD DE LAS GENTES DEL MAR: ESCORBUTO}

Los testimonios más tempranos atestiguados en lengua española para el término escorbuto revelan que se trata de un galicismo. Ciertamente, esta voz penetra en el español a través del francés a comienzos del siglo XVII, en concreto, a partir de la traducción de Historia de los milagros de nuestra Señora de Monteagudo de Sichen de Velpius realizada por Clemente (1606, p. 104):

Como sano una muger de cierta enfermedad, que el vulgo por aca llama Scorbuto, en Agosto de 1603. A Elizabeta de Houen, muger de Zacharias de Anroye vezina de la Aldea de Grasen junto à Betz al quartel de Dieste, le vino en las carnes tollendas del año 1603 un accidente y enfermedad que le causó grandes punçaduras por todo el cuerpo.

No obstante, el étimo remoto de esta voz parece ser la forma *scôrbut procedente del neerlandés medieval, que podría haberse tomado a través del sueco skörbjug o del nórdico skyrbjúrg 'escorbuto' (compuesto de skyr 'leche cuajada' y bjúrg 'edema', $D E C H$, s. v.). Así pues, la motivación designativa que subyace en este vocablo parte de un histórico criterio etiológico, dado que, según apuntan un buen número de los textos en los que se consigna este término, la aparición de los edemas característicos de esta enfermedad en los marineros podría deberse al consumo excesivo de leche cuajada durante sus largos viajes (TLF, s. v. scorbut).

En efecto, entre los tratados en español del setecientos y del ochocientos, especialmente, se difunde la idea de que el escorbuto es una enfermedad epidémica propia de marineros y navegantes que, además de múltiples dolencias, hemorragias, úlceras en las encías y la habitual pérdida de la dentadura, llegaba a causarles, en la mayoría de los casos, la muerte ${ }^{4}$.

Su aparente naturaleza contagiosa se debe a que los afectados convivían y subsistían en las mismas circunstancias durante las largas travesías en alta mar, con dietas en las que no figuraban fruta fresca ni hortalizas y, en consecuencia, la mayoría de navegantes de la época de los descubrimientos acababan padeciendo este mal:

Muchos se burlan de los nuevos establecimientos Rusos, porque a veces se observan en ellos enfermedades, no debiendo estrañar, que en un transporte de tantos hombres, mugeres y niños, caygan enfermos algunos de los transmigrantes. Por ventura se abandona el comercio, ni los vigilantes maritimos, aunque el scorbuto y otras enfermedades acometen à los $\mathrm{Na}$ vegantes (Anónimo, "Noticias países del norte", Mercurio Histórico y Político [Madrid], 01/10/1766).

Asimismo, entre los repertorios lexicográficos hispánicos coetáneos se consigna y define escorbuto como una enfermedad "que comunmente dá en el mar" (Terreros, s. v.),

causada por la obstrucción del brazo, que impide la atraccion del humor melancólico, el qual mezclado con la sangre daña y corrompe el cuerpo, y especialmente salta a las encías y las inficiona y vicia, de calidad que los dientes se caen (Autoridades, s. v.).

Sin embargo, con el avance de la práctica y de la investigación en materia médica, se constata que, en realidad, la etiología de esta enfermedad es el déficit de ácido ascórbico (o vitamina $\mathrm{C}$ ) en el organismo:

La falta de vitamina C produce el escorbuto, enfermedad que se observa entre las colectividades sometidas al uso de conservas o dietas muy restringidas, tal es el caso de las tripulaciones de los barcos que realizaban largos viajes; los sitios de las ciudades durante las guerras, etc. (Martínez Llopis, 1961, p.103).

Según los investigadores, la vitamina $C$ es necesaria para la dieta o para combatir algún principio de escorbuto (enfermedad general producida por la escasez 
o ausencia en la alimentación de determinados principios vitamínicos) (Anónimo, "Tomar vitamina C", El Tiempo [Bogotá], 01/10/2008).

De ahí la producción de bebidas compuestas, eminentemente, por limón, como preventivo antiescorbútico, que comenzaron a proliferar y a ser suministradas a las tripulaciones:

De ese alcohol de sabor fuerte y color acaramelado que se fabricaba en las Antillas para los negreros, del azúcar con que ellos se avituallaban junto con los tasajos, bacalao y demás salazones y conservas para las largas travesías, y de los limones que embarcaban los barcos veleros para impedir a bordo las epidemias de escorbuto, surgió espontáneamente una bebida compuesta, típica de los buques de la trata (Ortiz, 1963, p. 30); entre otras muchas hortalizas y vegetales con propiedades y nutrientes ricos en vitaminas, como el mastuerzo silvestre, el berro y la coclearia. De hecho, esta última es conocida, popularmente, como "hierba del escorbuto".

De acuerdo con Font Quer, en su libro Plantas medicinales (1962, p. 264), este género de hierbas florece desde marzo en adelante. Se cría en terrenos pedregosos o arenosos, húmedos, en el limo y en sitios fangosos del litoral, en las costas cantábricas de la Península, más bien rara y escasa. En otros tiempos, esta planta fue sometida a cultivo, como especie medicinal, y, a veces, persisten todavía descendientes cimarrones acá y allá. Contiene un glucósido sulfurado y el fermento llamado mirosina, que lo descompone y produce una especie de esencia de mostaza, el isosulfocianato de butilo. Contiene también vitamina C. En Medicina se ha venido utilizando esta planta como uno de los mejores antiscorbúticos. El nombre inglés de "scurvy grass" y el alemán de "Skorbutkraut", esto es, "hierba del escorbuto", aluden a aquella virtud de la coclearia, que hemos de atribuir a la notable cantidad de vitamina $\mathrm{C}$ en ella contenida.

Si bien el escorbuto se considera casi erradicado desde finales del siglo XIX, en la actualidad aún se presentan - de modo puntual y esporádico- casos de hipovitaminosis producidos por un aporte insuficiente de ácido ascórbico prolongado en el régimen alimenticio, como el que se relata en la siguiente noticia publicada en El Español (Madrid), en junio de 2016:

El escorbuto no ha desaparecido en los países civilizados, aunque los casos en los que suele darse son muy raros. En España, la literatura clínica había descrito casos aislados en 2001 ó 2004, siempre en pacientes mayores, con más restricciones dietarias y por tanto más vulnerables a esta vieja enfermedad, provocada por una deficiencia grave en el consumo de vitamina C. En enero de este año, el caso de un niño afectado por escorbuto en Valencia llegó como noticia a muchos medios de comunicación. Sin embargo, no fue el único. Poco después, en el Hospital Vall D’Hebrón de Barcelona, un hombre de 28 años era diagnosticado con la misma enfermedad [...]. "Se me ocurrió esta posibilidad", reconoce Loureiro, "pero ni yo ni ninguno de los médicos que vio este paciente había visto antes un escorbuto, de ahí la gracia, porque aún siendo rara, es una entidad de esas que se reconocen a simple vista de haberla leído en los textos clásicos de Medicina", concluye (Villareal, "Cómo diagnosticar hoy una dolencia de piratas", 08/06/2016).

\subsection{SUBTIPOS O VARIEDADES HISTÓRICAS DE ESCORBUTO}

Por lo que respecta a la historia del término escorbuto, cabe reseñar que, en el periodo comprendido entre 1733 y 1890, se atestigua, divulgada en diversos tratados médicos y artículos especializados en el ámbito de la medicina españoles, una taxonomía de los presuntos tipos o especies de escorbuto, en la que se especifican una serie de características particulares asociadas a la sintomatología de esta enfermedad. A continuación, expondremos una síntesis con algunos de los subtipos de escorbuto documentados más significativos ${ }^{5}$.

\subsubsection{Escorbuto terrestre ${ }^{6}$ vs. escorbuto marítimo ${ }^{7}$}

Como puede leerse en el primer volumen de Nuevos elementos de cirujía y medicina, de autoría anónima, hace unos siglos se consideraba que el escorbuto era una enfermedad que, además de epidémica, dependía de una "alteración especial de la sangre" (1846, p. 370). En consecuencia, algunos patólogos lo dividieron en "terrestre y marítimo, caliente y frío" (1846, p. 370).

Así pues, entre los testimonios consignados se distingue un tipo de escorbuto que provoca la inflamación de todos los órganos y fiebre - además de la aparición de múltiples hemorragias, anemia y úlceras en las encías-, esto es, el escorbuto caliente o terrestre, frente a otro tipo de escorbuto, designado frío o marítimo, que, en cambio, se caracteriza por la ausencia de estos signos. Este último se atribuye, como se señala en la adaptación de un artículo del Dr. Foltz publicado en el Boletín de Medicina, Cirugía y Farmacia (Madrid) del 15 de diciembre $1850^{8}$, "a la poca y mala ventilación de los buques, a la larga permanencia en el mar, a la humedad y frío, a la escasez y la falta de alimentos frescos, uso de carne salada y pescados, etc."; de ahí su denominación. 
Asimismo, se establece una comparativa, e incluso, una gradación de la intensidad o gravedad de las dolencias que estas variantes de la enfermedad desencadenan en aquellos que la padecen:

Como los symptomas son mas crueles en el escorbuto del mar que en el de tierra, se debe medir la atención sobre este principio general; porque unas sangrías hechas con tiempo previenen muchas veces el de tierra, disminuyendo la masa de los humores, dándoles la libertad de circular sin tanto obstáculo (Rancé, 1773, p. 237).

Se ha querido establecer una distinción entre el escorbuto de tierra y el escorbuto de mar. Los síntomas son los mismos; solo que, por las razones ya enunciadas, en el mar las alteraciones son frecuentemente mas graves. Se ha dado el nombre de escorbuto frio al que hemos descrito aquí, y de caliente al que va acompañado de fiebre ó de flegmasías de diversos órganos (Anónimo [trad.], Enfermedades generales y diátesis, 1853, p. 407).

Con todo, ya en el ecuador del siglo XIX se puntualiza lo siguiente:

Se cree en el dia que el escorbuto de mar y el de tierra son idénticos y que la presencia de síntomas inflamatorios (escorbuto caliente) ó la falta de los mismos (escorbuto frio) nada tienen que ver con el carácter constante de la enfermedad; de lo que resulta no admitirse mas que un escorbuto: tampoco se le considera hoy contajioso como se le creyó en otras épocas (Anónimo, Nuevos elementos de cirujía y medicina, 1846, p. 370).

\subsubsection{Escorbuto petequial vs. escorbuto cárdeno, lívido o aplomado}

Por otro lado, en la Disertación médico-histórica sobre la elefancia, se describen otras dos clases de escorbuto y se establece un símil entre las mismas y la elefantiasis, motivado por la semejanza que manifiestan algunos de sus síntomas:

El mismo observador describe otras dos clases de escorbuto: uno cárdeno, y otro petechial, esto es, pintado ó con manchas; ámbos en cierto modo semejantes á la elefancia, pues en las dos se hinchaban las sienes y las glándulas parótidas; las cejas y las pestañas se ponian roxizas, de manera que el semblante de estos enfermos se parecia al de los sátiros, exhalando su cuerpo un hedor intolerable (1786, p. 233).

A este propósito, en la traducción de los Elementos de medicina práctica de Cullen llevada a cabo a finales del siglo XVIII por Piñera Siles, se especifica que, en el escorbuto petequial -y a diferencia del lívido o aploma- do, "caracterizado por grandes manchas negras y azuladas, que se descubren en las piernas y las coyunturas, alguna vez en el dorso y el pecho, y aun las mas veces en los párpados" (1792, p. 231)-,

las manchas tienen un roxo socuro, que despues se muda en un color pajizo negrusco. Estas manchas son muy pequeñas, y se parece á picaduras de pulgas ó á petecîas; solo salen en la parte anterior de las piernas, y en los tobillos, y estan acompañadas de dolor (1792, p. 231).

\subsubsection{Escorbuto pedregoso o topáceo}

También en la Disertación sobre la elefancia - de autor desconocido- se consigna otra variante escorbútica adicional que se caracteriza por la aparición de acné, aunada al cuadro general de síntomas que desencadena esta enfermedad ya citado $(\S 2)$ :

El suero de la sangre salia turbio, siendo este género de escorbuto mas crónico que los demas, pues duraba todo el verano y bien entrado el otoño. Dividelo el citado Médico [el Doctor Nitsch] en [...] tophaceo ó pedregoso quando salian á la cutis granos ó puerros (1786, p. 232).

\subsubsection{Escorbuto muriático}

En esta misma obra se describe, además, otro tipo de escorbuto: el muriático, el cual se aprecia "quando las ternillas y huesos de la nariz estaban roidos ó carcomidos" (1786, p. 233). Sin embargo, como recalca y desmiente, poco después, Piñera Siles, en la traducción al español del Tratado teórico y práctico de las úlceras o llagas de Bell,

las diferentes especies de escorbuto de que hacen mencion los Autores, como el muriático, el alkalino, \&c llamados de este modo por razon de las causas que se suponen capaces de producirlas, estan hoy reconocidas por distinciones del todo falsas é impropias. El verdadero escorbuto es siempre de la misma naturaleza, se produce por las mismas causas en qualquier parage, y en qualquier clima que se encuentren, tanto en la tierra, como en el mar (1790, p. 242).

\subsection{Del escorbuto a LA PELAgRA (O escorbuto alPinO)}

Por último, documentamos la lexía compleja escorbuto alpino, aunque en este caso no se trata, como confirman los testimonios atestiguados, de una variante de escorbuto, sino de una denominación histórica de la -también hipovitaminosa- enfermedad de la pelagra, causada por la falta de vitamina B3 o de algún 
aminoácido en la alimentación que provoca lesiones de la piel, alteraciones mentales y problemas gastrointestinales. De hecho, como enumera Alfaro (1840, p. 458), este compuesto sintagmático es uno más entre el nutrido conjunto de sinónimos que ofrece la literatura científica que versa sobre esta patología ("pelagra = dermatagra, erisipela nerviosa, calor del hígado, mal de miseria, escorbuto alpino").

Asimismo, entre los ejemplos espigados, se certifica que esta denominación fue acuñada por el profesor de la Universidad de Padua, Giuseppe Antonio Pujati (1701-1760), quien consideraba, por equivocación, esta enfermedad endémica de los estados venecianos y de Lombardía; cuando, en realidad, fue descubierta al menos dos décadas antes, en 1762, por el doctor español Gaspar Casal (1680-1759), quien la denominó mal de la rosa, tal y como puede leerse en la monografía póstuma dedicada a esta enfermedad en la que se estudia y consigna por vez primera (1848). Precisamente, la mayoría de los testimonios documentados son de carácter historiográfico y se hacen eco de este hecho (así como de su pluralidad designativa):

La pelagra no apareció en Europa antes del siglo XVIII, pero desde esta época se presentó bajo la forma endémica, en Asturias ( $m a l$ de la rosa), en Lombardía y en los Estados venecianos (escorbuto alpino) y se propagó por Francia en las Landas ( $m a l$ de la Teste), los Pirineos, los departamentos del Alto Garona y los Andes, y por algunos otros (Espina Martínez [trad.], 1867, p. 498).

Thierry, médico de la Embajada francesa, que después de haber conocido á Casal, y tenido por él noticia de este padecimiento, asistió á una enferma de pelagra en 1753, fué el primero en Francia que hizo y publicó un estudio acerca de este asunto; y el escorbuto alpino, descrito veinte años después por Rijati, refiriéndose a una rara enfermedad observada en el distrito de Feltro, en los Estados de Venecia, y lo que llamó Lauvages lepra asturiana, el mal del hígado de las provincias aragonesas, como el mal de la rosa de Asturias, y la flema salada de Castilla la Nueva, y el salso de los italianos, son una misma cosa: la enfermedad que hoy es conocida universalmente con el nombre de pelagra (Moliner, "Variedades: De la pelagra", Revista Ibero-Americana de Ciencias Médicas [Madrid], 01/12/1903).

\section{OTRAS DENOMINACIONES}

\subsection{LOANDA / MAL DE LOANDA}

Aproximadamente en 1618, en los Comentarios de Silva Figueroa, se describe una "enfermedad, por la mayor parte es peligrosissima y terrible, á que comunmente llaman mal de Loanda" (p. 85), la cual:

hinchandose las piernas y muslos, con unas manchas negras ó moradas de malisima y oculta calidad, subiendose desde alli poco á poco al vientre y luego al pecho, á donde luego mata, sin otro dolor ó calentura, sino son aquellos que por tener robusta conplexion escapan $(1618$, p. 85$)$

Con todo, este compuesto sintagmático se consigna a menudo junto a la voz escorbuto y la conjunción disyuntiva $o$, para establecer la equivalencia semántica que se produce entre ambas denominaciones, como se constata en el siguiente ejemplo:

Pero no son estos los únicos daños que se siguen en los hospitales generales; otros hay mucho mas graves y funestos, como son las calenturas pestilentes, y el escorbuto ó mal de Loanda, que en ellos se origina de la corrupcion del ayre, que los enfermos respiran lleno de sus mismas exhalaciones (Bails [trad.], 1798, p. 147).

Así, en el Tratado de enfermedades de la gente mar se afirma que se trata de una expresión popular divulgada por:

los marineros portugueses, de quienes lo han tomado los españoles, llaman vulgarmente á esta enfermedad mal de Loanda, porque los primeros de sus paisanos que abordaron con Vasco de Gama á aquellas costas de Africa, la contraxeron por la primera vez; y creyéndola exclusiva de aquella provincia, diéron con justicia el propio nombre de su patria á un mal, que para ellos era absolutamente desconocido (González, 1805, p. 215).

En efecto, en la cuarta edición del DRAE, publicada en 1803 , se define la voz loanda como una "especie de escorbuto" (s. v.) que se consideraba endémico de la región que le da nombre: Loanda (o Luanda, en la actualidad), topónimo acuñado por el explorador portugués Dias de Novais, en 1575, al fundar, junto con un medio centenar de soldados y familias de colonos, esta ciudad africana (hoy capital de Angola).

\subsection{BERBÉN}

Al menos desde 1680, en la Breve relación de la peregrinación que ha hecho de la mayor parte del mundo de Cubero Sebastián, se atestigua el término berbén como sinónimo de mal de loanda (o escorbuto), inserto en un fragmento en el que se relata que este fue uno de los males más pestíferos que aquejaban a los navegantes. Se trata de una voz de origen desconocido; quizá del portugués berber ${ }^{9}$, tal y como se postula en algunos testimonios próximos a la llegada de los 
lusos a las islas Molucas (Indonesia), en 1511. De hecho, cabe señalar que, en varios de los testimonios hallados, el berbén aparece descrito, por error, como una enfermedad endémica y contagiosa del Sudeste Asiático:

pero llegó providencialmente de Manila la Animo$s a$, los proveyó de lo necesario, y trajo por mar las dos compañías expedicionarias, aunque con algunas bajas, habiendo fallecido asimismo algunos tripulantes de la Valiente atacados de un mal que por las señas es el que antiguamente se llamaba por esta tierra berben y mal de Loanda, y ahora se conoce con el nombre de escorbuto (Anónimo, "Relación del viaje del reverendo Padre Fernández Cuevas [...]", El Pensamiento Español [Madrid], 01/01/1864);

que, debido a las expediciones de los navegantes, fue trasladada a América (en concreto, al Virreinato de Nueva España), como explica (Clavijero, 1780) en Historia antigua de México:

Del mal venéreo, hablaremos en otra disertación, y respecto a las otras enfermedades, yo le concedo que en la vasta extensión de América haya algunos países en los cuales los hombres están más expuestos que en otras partes a ciertas enfermedades causadas por la intemperie del aire o la mala calidad de los alimentos; pero lo cierto es que, según muchos graves autores conocedores del Nuevo Mundo, los países americanos, son, en su mayor parte, sanos, y que si los americanos quisieran corresponder a Paw y a otros europeos que escriben como él, tendrían una gran colección de buenos materiales para desacreditar el clima del Antiguo Continente y la complexión de sus habitantes en tantas enfermedades endémicas que hay en él, como la elefantiasis y la lepra de Egipto y de Siria, el vérben del Asia meridional, el dragoncelo o gusano de Medina (1780, p. 511).

Por este motivo, no es de extrañar que el término berbén se consigne, a menudo, marcado diatópicamente como un americanismo o un mexicanismo en varios repertorios lexicográficos coetáneos: "verben, enfermedad, que da á los que navegan, especialmente de Asia á América, y con que se les hinchan las piernas y peligran" (Terreros, s. v.) y aún de los siglos siguientes: "Berbén. m. Méj. Loanda" (DRAE, 1925 [15a ed.]) o "Berbén. (Voz afr.). m. En Méjico, el escorbuto o mal de Loanda" (Santamaría, s. v.). De hecho, este último testimonio documentado en el Diccionario general de americanismos confeccionado por Santamaría en 1942 es, según nuestras pesquisas, la última aparición de este vocablo en lengua española, pues ya en los diccionarios decimonónicos de Domínguez (1853), de la editorial Gaspar y Roig (1855) o de Zerolo (1895) se apunta el carácter obsoleto de este término, definido como 'nombre antiguo del escorbuto' (s. v. berbén).

\subsection{MAL DEL GUSANILLO}

De manera análoga, otro de los sinónimos de mal de loanda es, según Montenegro, la adaptación del lusismo mal do vicho, popularmente conocido en español como mal del gusanillo. A este respecto, el autor advierte, antes de la detallada descripción de la sintomatología que provoca esta enfermedad, sobre el doblete sinonímico y diastrático que se establece entre esta formación vulgar (mal del gusanillo) vs. el término de especialidad que se emplea en la jerga médica (escorbuto):

Es el Mastuerzo silvestre uno de los únicos remedios que he hallado hasta hoy para los que padecen el mal de loanda, que el Portuguez llama mal do vicho, en otras partes llaman mal de gusanillo, y en las partes del norte, y clace medica llaman escorbuto, porque comiendo sus ojas crudas, ó puestas en enzaada, ó asi solas quita el comezon y dolor que viene á los dientes y paladar, y asi mismo la flaqueza y dolores de estomago:- y lebanta el apetito perdido:- corrije la hediondez del anhelito, provocando los humores por orina y camara, y deshaciendo la conjelacion de las reumas que se paran en los intestinos con graves dolores y pujos ó camaras, asi bebiendo su cocimiento como echande ayudas de él con sal y miel es unico remedio: [...] (1710, p. 386).

\subsection{PESTE DE(L) MAR}

Motivada -a nuestro juicio- por la gran mortandad que provocaba esta enfermedad entre marineros y navegantes, así como por la creencia histórica acerca de su carácter contagioso, se consigna la denominación popular peste del mar en varios testimonios historiográficos de mediados del siglo XX espigados. En estos se relata, entre otros hechos, el impacto de esta enfermedad en la tripulación de la expedición de Vasco de Gama en aras de averiguar una nueva ruta comercial a la India (1497), o en los colonos que participaron en la conquista de la Nueva España (1557), como puede leerse en los siguientes extractos:

Condiciones muy semejantes a las existentes en una ciudad por mucho tiempo sitiada, regían la vida en los barcos a vela durante largos viajes, provocando por la misma razón el escorbuto entre tripulantes y viajeros. En la famosa expedición de Vasco de Gama para abrir una ruta a las Indias Orientales, la tripulación pagó en distintas ocasiones un precioso tributo de vidas a ese mal que más tarde los marineros denominaron "peste del mar" (Kaiser, 1945, p. 104).

Bernal Díaz del Castillo cuenta cómo en el mercado 
de Tlatelolco vio esclavos cuyos brazos se apoyaban en un palo cruzado tras la nuca, como los portugueses traen a los negros de Guinea [...]. Los barcos negreros tenían varias plantas, cada una de dos pies de altura. Los esclavos iban tendidos y encadenados. Un tercio quedaba en la travesía porque el escorbuto los aniquilaba. Viejos autores cuentan que la enfermedad apareció en el siglo XIII y hacía estragos entre los marineros, que la llamaron peste del mar (Alvar, "Chicharrones, aguardientes y otras buenas compañías", ABC [Madrid], 14/07/1984);

de ahí que algunos escritores afirmen que las enfermedades padecidas o contraídas durante el tiempo de navegación, sobre todo, entre África e Hispanoamérica, "en ocasiones convertían los barcos en verdaderos hospitales" (Alzate Echeverri, 2007, p. 163).

En definitiva, el escorbuto fue, como señala Olivas Weston, durante casi cuatro siglos (del XV al XVIII), la causa de incontables decesos en los viajes transatlánticos ("las últimas explosiones epidémicas del mal se dieron a bordo de los buques de vela en largas travesías. Por esa razón se decía que la vela era sinónimo del escorbuto", 1996, p. 356). Sin embargo,

la transformación de esta marina en la de vapor, en la primera mitad del siglo XIX, señala el fin de "la peste del mar". Sin lugar a dudas, por la mayor rapidez con que se realizaban las travesías y porque la higiene era más rigurosa a bordo de los buques. A partir de entonces ciertos parajes como el Cabo de Buena Esperanza o el Cabo de Hornos, dejaron de llamarse los "Cabos del Escorbuto" (Olivas Weston, 1996, pp. 356-357).

\subsection{ESCELOTIRBE}

Por otro lado, destaca el cultismo escelotirbe ${ }^{10}$, documentado en 1629, en la traducción de la Historia natural de Cayo Plinio Segundo llevada a cabo por Huerta, en la que se narra la enfermedad que padecieron los soldados de César Germánico en las orillas del río Rin durante su paso por Alemania, consecuencia de las malas aguas que estos ingerían. No obstante, con este significado se registra esporádicamente, pues, a menudo, este término alude a otro tipo de enfermedad; en concreto, a la corea o baile de San Vito, de acuerdo con las investigaciones de Ballano, entre otros:

Escelotirbe: Corea. Esta enfermedad consiste en movimientos convulsivos, que son en parte voluntarios, y que acomete á los niños de ambos sexos, que no han llegado todavía á la edad de la pubertad, y mas á los que estan entre la edad de diez y catorce años. Estos movimientos afectan por lo comun el brazo y la mano de un solo lado, y parecen pantonímicos (Ballano, s. v.).
Escelotirbe [...] Esta enfermedad conocida vulgarmente con el nombre de danza de $\mathrm{S}$. Vito consiste en movimientos que participan de voluntarios, y acomenten á niños de ambos sexos desde los diez años hasta la época de la pubertad. Su invasion principia por una especie de cojera, ó por mejor decir, por movimientos continuos que acomenten á la pierna brazo de un lado, los cuales por mas que los enfermos permanezcan en quietud, son agitados ya hácia un lado, ya hácia otro, imitando los compases pantomímicos (Sanz Muñoz, 1820, p. 265).

En esta misma línea, en el Suplemento al Diccionario Nacional de Domínguez (1853) se define como "la flaqueza ó debilidad de las piernas" (s. v. escelotirbe).

\subsection{ESTOMACACE}

Igualmente, de raigambre culta ${ }^{11}$ y consignado en la traducción de Huerta acerca de la Historia natural de Plinio, se consigna el vocablo estomacace como un posible término histórico que se empleó en la descripción y caracterización del escorbuto:

En Alemania de la otra parte del Rheno, lleuando el Cesar Germanico su campo por la ribera, hallaron sola una fuente de agua dulce, la qual beuida dentro de dos años, se caían todos los dientes, y las junturas de las rodillas se desencajauan. Los Medicos llamauan a estos males stomacace, y sceletirbe. Hallóse para remedio una yerua, que se llama britanica, no solamente saludable para los neruos, y males de la boca, sino tambien contra las equilencias, y serpientes (Huerta, 1629, p. 375).

Así, este mal, procedente del norte, es, como relata Sanz Muñoz, propio de las gentes del mar o navegantes:

La estomacace es un fluxo de sangre por las encías. Esta enfermedad es propia del norte, de los navegantes. Tambien acomete á los melancólicos y á los enxutos de carnes. Quando esta enfermedad depende del virus escorbútico, se distingue por el hedor intolerable de la boca, por la espontánea expulsion de sangre de las encías, la erosion y podredumbre de estas, la caries y ennegrecimiento de los dientes, y su caida y demas síntomas del escorbuto. El poco aseo y el uso de alimentos de mala qualidad son freqüentemente causas de esta afeccion (1811, p. 250).

A este respecto, en varios de los testimonios atestiguados, se hace explícita la sinonimia o equivalencia que se da entre esta denominación y el galicismo escorbuto:

Estomacace, s. m.; de stoma boca y kakos mal, vicio; ulceracion fétida de la boca. se dá este nombre al escorbuto, á causa del mal estado de la boca en esta enfermedad. Segun Plinio los médicos antiguos dieron este 
nombre á una enfermedad que atacó á los soldados de Germánico-Cesar, que hicieron uso del agua de una fuente de la Germánia, donde se hallaban acampados (Castells [trad.], 1860, s. v.)

No obstante, en otros muchos textos y repertorios lexicográficos se alerta de que "es menester no confundir el escorbuto con la estomacace, la cual es un afecto catarral de la boca" (Diccionario de Ciencias Médicas, s. v.) y se considera que el estomacace no es más que un síntoma derivado de esta enfermedad:

En la Estomacace el aliento huele mal, las encías estan ulceradas, y la sangre sale espontáneamente de ellas; freqüentemente hay carie en los huesos de las quixadas, y un babeo hediondo, los dientes se menean y se caen; la Estomacace á menudo es un síntoma del escorbuto, ó de algun vicio de lo interior de la boca; ataca alguna vez á los niños criados en los hospitales que estan mal alimentados y sucios; es epidémica en estos parages, y reyna al mismo tiempo que las enfermedades catarrales (Piñera Siles [trad.], 1789, p. 404).

E incluso hay quienes corroboran que los médicos griegos, romanos y árabes desconocieron del todo el escorbuto:

La enfermedad de que habla Plinio con el nombre de estomacace y que devastó el ejército Germano acampado en las orillas del Rhin inmediatas al mar, afirman muchos que no fué el escorbuto, ni tampoco lo fué el mal que padecieron los soldados de S. Luis, en Egipto. Parece que la primera relacion que se encuentra del escorbuto, es en el viage de vasco de Gama á las Indias Orientales, por el Cabo de Buena-Esperanza, y la obra en que primero se trató de semejante enfermedad, es en la de Juan de Ecthio, en donde señala como causa de ella, la mala nutricion y una alteracion de la sangre (Drumen, 1850, p. 222).

Los amantes de la venerable antigüedad; los que militan baxo la especiosa divisa de nihil sub sole novum pretenden que Hipócrates habló del escorbuto, hablando de las enfermedades del bazo; y aun descendiendo á épocas mas recientes creen encontrarlo en los historiadores latinos. Plinio y Estrabon, aquel tratando de los exércitos que mandaba César Germánico en Flandes, y este del que militaba en la Arabia á las órdenes de Elio gallo, dicen que estos exércitos fuéron acometidos de una exulceracion de boca llamada entónces stomacace, y tambien de una especie de paralísis, que sobrevenia en los extremos inferiores, y se denominaba scelotyrbe. No contentándose otros con aquellas descripciones defectuosas respecto al escorbuto, y que efectivamente no dan á conocer su verdadero carácter, ni idea alguna de la curacion que puede serle mas apropiada; [...] (González, 1805, pp. 215-216)
Dado que el estomacace es, simplemente, una "ulceración y fetidez de la boca", según Hurtado de Mendoza (Vocabulario médico-quirúrigico o Diccionario de medicina y cirujía, s. v.), entre otros especialistas (cf. Floch, "Discurso", Revista de las Españas [Madrid], 30/04/1845).

\subsection{GINGIBRAQUIO}

Asimismo, entre la nómina de sinónimos de escorbuto de origen latino, sobresale el término gingibraquio, definido por Hurtado de Mendoza, en su diccionario médico (1840) -y por vez primera en lengua española-, como un escorbuto cuyos principales estragos se verifican principalmente en las encías y en los brazos.

Al parecer, según revelan los testimonios consignados, este vocablo fue acuñado en el quinientos por el médico Pieter van Foreest -más conocido por su nombre latinizado, Petrus Forestus, o como el "Hipócrates holandés" - , a partir de un criterio anatomopatológico (del lat. gingīva 'encía' y brācchium 'brazo'12), en su estudio sobre la naturaleza del escorbuto del siglo XVI (apud For. I. 20 Obs. II. in Schol.). Para Forestus, el término gingibraquio, el cual fue divulgado, posteriormente, por Bartolomeo Castelli en el Lexicon medicum graeco-latinum (1746: 364), designa un subtipo de escorbuto cuya sintomatología afecta, de manera exclusiva, a estas dos partes de la anatomía (cf. Novísimo diccionario de la lengua castellana con la correspondencia catalana, II, 1866).

No obstante, dado que la aparición de úlceras en las encías y la inflamación de las extremidades constituyen los síntomas prototípicos de la enfermedad objeto de este estudio, hay autores que consideran que este término se trata, en realidad, de un sinónimo de escorbuto (cf. Domínguez, Compendio del Diccionario nacional de la lengua española, II), sin mayor especificidad. Probablemente, esta fue la causa que generó la escasa aceptación de este neologismo entre los especialistas y la divulgación médica, dado que apenas circuló, perpetuado desde la aportación de Hurtado de Mendoza, en una serie de diccionarios hispánicos decimonónicos y de las dos primeras décadas del siglo XX (Domínguez 1847 y 1852; Salvá, 1879; Zerolo, 1895; Alemany Bolufer, 1917 y Rodríguez Navas, 1918).

\subsection{GINGIPEDIO}

De manera análoga, en el diccionario terminológico que confeccionó Hurtado de Mendoza en 1840 se consigna el correlato o variedad de escorbuto para el caso de las extremidades inferiores, esto es, el gingipedio ${ }^{13}$ (a partir del latín gingiva 'encía' y pes, pedis 'pie'), pues, como explica el autor, "los miembros inferiores son en muchos casos el asiento de manchas escorbúticas". 
Efectivamente, entre la documentación recopilada se indica que este tecnicismo - acuñado en el siglo XVI por Forestus - da nombre a una especie de escorbuto cuyos síntomas se localizan - además de en las encías - en las extremidades inferiores, en las que aparecen una serie de manchas, de modo similar al escorbuto aplomado o lívido (que genera la aparición de grandes manchas negras y azuladas en las piernas, las articulaciones, el pecho y los párpados, § 2.1.2) o escorbuto petequial (caracterizado por la aparición de manchas muy pequeñas de color rojo en el pecho y las extremidades, § 2.1.2). Con todo, esta taxonomía y nomenclatura que propuso Forestus en su exhaustivo estudio sobre el escorbuto no triunfó en el ámbito de la terminología médica, tal y como confirma la escasa documentación de este término.

\subsection{Pequitirbo}

Finalmente, entre la nómina acuñada por el célebre médico holandés en relación a esta enfermedad avitaminosa, destaca el vocablo pequitirbo ${ }^{14}$ (formado a partir del griego pēchy 'codo' y -tyrbe 'desorden') que, como señalan Hurtado de Mendoza y Martínez Caballero en el Suplemento al Diccionario de Medicina y Cirugía, del profesor Ballano, (1817) es el 'nombre que han dado algunos autores, y señaladamente Forestus, al escorbuto' (s. v. pechitirbo).

Pese a la relevancia de la obra confeccionada por Forestus, esta denominación alternativa que propuso para referirse a la enfermedad propia de marineros y navegantes por antonomasia no triunfó; de hecho, apenas queda registrada en una decena de diccionarios especializados en el ámbito de la medicina de distintas lenguas extranjeras publicados en el siglo XIX (como The Philadelphia Medical Dictionary, de Redman Coxe, 1817; Dictionnaire des termes de médecine, chirurgie, art vétérinaire, pharmacie, histoire naturelle, botanique, physique, chimie, de Bégin et al, 1823 o el Dizionario classico di medicina interna ed esterna, de Levi, 1840, entre otros).

\section{CONCLUSIONES}

Como se ha procurado poner de manifiesto en este estudio, la terminología médica relativa a la enfermedad de las gentes del mar en la historia del español es prolífica y variada ${ }^{15}$. Por lo que respecta a la etimología de las voces estudiadas, entre las mismas destacan una serie de lusismos procedentes de las primeras descripciones de esta enfermedad (berbén, loanda, mal de loanda) y de expresiones populares adaptadas del portugués (mal del gusanillo) o motivadas por la gran mortandad que esta afección generaba en las tripulaciones de las navegaciones transatlánticas (peste del mar), así como un nutrido conjunto de cultismos de cariz grecolatina (estomacace, escelotirbe, gingibraquio, gingipedio, pequitirbo ${ }^{16}$ ) y el galicismo escorbuto, el cual se erige, ya desde comienzos del siglo XVII, como la denominación propia de la jerga médica.

Con todo, tal y como se certifica en la documentación expuesta y analizada, no siempre hay consenso entre los especialistas acerca de la equivalencia semántica entre este conjunto de términos (por ejemplo, hay quienes consideran que los términos escelotirbe, estomacace, gingibraquio o gingipedio son sinónimos de escorbuto y otros que, por el contrario, niegan tal relación) ni acerca de la existencia de variantes o subtipos del escorbuto como las que proliferan en varios tratados de los siglos XVIII y XIX (escorbuto terrestre, marítimo, petequial, muriático, etc.) o sobre las primeras descripciones de esta enfermedad (dado que hay autores que postulan que Plinio e Hipócrates la conocieron y la describieron, frente a otros que desmienten rotundamente esta posibilidad).

Asimismo, entre los textos y los testimonios espigados se observa la evolución que la caracterización de esta afección ha experimentado con el paso del tiempo, la cual avanza desde la creencia de que la ingesta de leche cuajada o agua pútrida en altamar era la causa que la provocaba y que presentaba un carácter contagioso (de ahí, la denominación peste del mar) y endémico (de África [por ello, los nombres loanda o mal de loanda] o Asia, trasladada, después, a América) hasta el conocimiento científico y riguroso acerca de su etiología y naturaleza que hoy se maneja.

En suma, se advierten diversos procedimientos neológicos de interés para un mejor conocimiento del léxico médico del pasado, como los motivados por un criterio anatomopatológico (gingibraquio, gingipedio, pequitirbo), etiológico (escorbuto y sus presuntos derivados: terrestre y caliente, marítimo y frío, petequial, aplomado) o fisiopatológico (escelotirbe, estomacace) correspondientes a las sucesivas etapas por las que la medicina fue transcurriendo en estos últimos cuatro siglos de su historia.

\section{AGRADECIMIENTOS}

Este trabajo se inserta en las líneas de desarrollo del proyecto del Nuevo Diccionario Histórico del Español (NDHE) de la Real Academia Española. Asimismo, estas investigaciones se integran dentro del proyecto $\mathrm{I}+\mathrm{D}+\mathrm{i}$ : "Programación de un Tesoro Lexicográfico Médico en lengua española y de su explotación, a partir de diccionarios médicos del siglo XIX y principios del XX" (Ref.: PGC2018094266-B-100). 


\section{NOTAS AL FINAL}

1 En especial, testimonios recuperados a partir de la Biblioteca digital hispánica (en adelante, $B D H$ ) de la Biblioteca $\mathrm{Na}$ cional de España.

2 Nos serviremos, sobre todo, de los siguientes bancos de datos académicos: $C D H, C O R D E, C R E A, C O R P E S$.

3 Consignados en el Nuevo Tesoro lexicográfico de la lengua española (NTLLE), así como en el Mapa de diccionarios académicos de la Real Academia Española.

4 Y así se recreará, con suma frecuencia, en la literatura: "el escorbuto se llevaba cuatro o cinco cada día; nos amenazaba un asalto; cada noche nos parecía que iba a ser la última de nuestra vida miserable" (Fernández de Moratín, Cartas, 1814, p. 297 [véase $C D H$ ]). Asimismo, las consecuencias del padecimiento de esta enfermedad le servirán a García Márquez para recrear y caracterizar al personaje de Melquíades en Cien años de soledad: "se quejaba de dolencias de viejo, sufría por los más insignificantes percances económicos y había dejado de reír desde hacía mucho tiempo, porque el escorbuto le había arrancado los dientes" (1967, p. 14 [véase $C D H]$ ).

5 Para más información, véase $N D H E$, s. v. escorbuto [subacepciones].

6 También denominado [escorbuto] alcalino, caliente, esténico, febril, inflamatorio, salino o escorbuto de tierra.

7 También denominado [escorbuto] ácido, asténico, elefancíaco, lento, frío o escorbuto de(l) mar.

8 Se trata, como se explicita en esta noticia obtenida de la $B D H$ (BNE), de "un estracto un artículo publicado sobre este asunto en la Prensa médica de Dublin por el Dr. Foltz que consiste en una larga é importante descripcion del Escorbuto de mar".

9 "Documentado ya en 1665, cuando se registra en Voyages en Afrique, Asie, Indes Orientales \& Occidentales de Mocquet ("cari'eus encor ceste fascheuse \& dangereuse maladie de louende que les Portugais appellent autrement berber, \& les Holandois scurbus», p. 221)" (NDHE, s. v.)

10 "Voz tomada del latín scelotyrbē, documentada en esta lengua al menos desde 1518, cuando se registra en Pedacii Dioscoridae Anazarbei de Medica materia liber sex traducido

\section{BIBLIOGRAFÍA}

Alemany y Bolufer, José (1917), Diccionario de la lengua española, Barcelona, Ramón Sopena.

Alfaro, Nicolás de (1840), Tratado teórico práctico de enfermedades cutáneas, I, Madrid, Imprenta de Yenes.

Alzate Echeverri, Adriana Mar (2007), Suciedad y orden: Reformas sanitarias borbónicas en la Nueva Granada 1760-1810, Bogotá, Editorial Universidad del Rosario.

Anónimo (1786), Disertacion medicohistorica sobre la elefancia, y su distinción de la lepra; con noticias acerca del escorbuto, fuego de S. Anton, peste, lue venerea y otras dolencias cutáneas inmundas, y la historia fisica de los tiempos y climas, Madrid, Imprenta de Pacheco.

Anónimo (1846), Nuevos elementos de cirujía y medicina, por algunos doctores en ambas ciencias, II, Madrid. por M. Virgilio (Florentiae, P. Juntae); y esta, a su vez, de griego skelotýrbē (cf. OLD, s. v.)" (NDHE, s. v. escelotirbe).

11 "Voz tomada del latín científico stomacacce, atestiguada al menos desde 1518, cuando se registra en De medica materia: libri sex de Dioscórides traducida por M. Virgilio (Florentiae, per haeredes P. Juntae, p. 221: «morbis in Germanici Caesaris exercitu trans Rhenu [...] volumine capite tertio, pdidit Malaq; duo illa stomacaccem \& Scelotyrbem vocavit»)" (NDHE, s. v.).

12 "Voz tomada del latín científico gingibracchium, atestiguada en esta lengua al menos desde 1691, cuando se registra en la Encyclopaedia medica dogmatica de J. Doläus (Francofurti ad Moenum, Friderici Knochii, p. 625: «Foresto placet Gingibracchium appellare, cum \& bracchia interdum afficiat: ab aliis \& dicitur gingipendium, quod gingivas \& pedes infelter $) "$ (NDHE, s. v. gingibraquio).

13 "Voz tomada del latín científico gingipedium, atestiguada en esta lengua al menos desde 1564, cuando se registra en De magnis Hippocratis lienibus, Pliniique stomacace ac scelotyrbe, seu vulgo dicto Scorbuto, Libellus de B. Ronsseo Gandensi (Antverpiae, Vidum Martini Nutii, p. 28: «Gingipedium quibusdam ficto nomine dicitur, á Gingivis et pedibus corrupto sanguine infectis quam; sanguinis mundificativa recte ad curandi rationem exhiberi»)" (NDHE, s. v. gingipedio).

14 "Voz tomada probablemente del francés péchytyrbe, atestiguada en esta lengua al menos desde 1747 , en el tomo $V$ de la traducción, a partir del inglés, del Dictionnaire universel de medecine, de chirurgie, de chymie, de botanique, d'anatomie, de pharmacie, d'histoire naturelle, \&c. de M. James realizada por Diderot, Eidous y Toussaint (Paris, Briasson, p. 389: "Pechytyrbe, épithete qu»on donne au scorbut. Castelli dıaprès Forestus»)" (NDHE, s. v.).

15 En el reciente DTM de la RANM, entre otros muchos diccionarios especializados en materia médica, a excepción de los confeccionados por Hurtado de Mendoza (1823 y 1840), solo se consigna el término escorbuto.

16 Conviene reseñar, a propósito de estas voces, la aportación que supuso la obra de Hurtado de Mendoza, pues, gracias a su diccionario terminológico, tenemos constancia de las mismas. Sobre este aspecto ha trabajado Gutiérrez Rodilla (véanse, entre otros, sus trabajos de 2012a, 2012b y 2017).

Anónimo [trad.] (1853), Enfermedades generales y diátesis [...] por P. N. Gerdy, Madrid, Imprenta y estereotipía de M. Rivadeneyra.

Anónimo [Sociedad Literaria] (1866), Novísimo diccionario de la lengua castellana con la correspondencia catalana redactado con presencia del de D. Pedro Labernia. II, Madrid, Espasa.

Autoridades = Real Academia Española (1726-39), Diccionario de autoridades, Madrid, Joaquín Ibarra.

Bails, Benito [trad.] (1798), Tratado de la conservacion de la salud de los pueblos, y consideraciones sobre los terremotos, de Antonio Nunes Ribeiro, Madrid, Imprenta de la Viuda de Ibarra.

Ballano, Antonio (1817), Diccionario de medicina y cirugía, ó biblioteca manual médico-quirúrgica, IV, Madrid, Fco. Martínez Dávila.

Bégin, Louis-Jacques; Boisseau, François-Gabriel; Jourdan, Antoine J. Louis; Montgarny, Jean-Baptiste (1823-1830), Dic- 
tionnaire des termes de médecine, chirurgie, art vétérinaire, pharmacie, histoire naturelle, botanique, physique, chimie, etc., Paris, Chez Béchet, Baillière, Crevot.

Biblioteca Nacional de España (2016), Biblioteca digital hispánica, [en línea], disponible en: http://www.bne.es, [consultado el: 03/11/2019].

Castelli, Bartolomeo (1746), Lexicon medicum graeco-latinum, Genevae, Fratres de Tournes.

Castells, José [trad.] (1860), Diccionario de Medicina, Cirugía, Farmacia, Medicina legal, Física, Química, Botánica, Mineralogía, Zoología y Veterinaria, por P. H. Nysten, II, Barcelona, Imprenta de J. Roger.

$C D H=$ Instituto de Investigación Rafael Lapesa de la Real Academia Española (2013-), Corpus del Nuevo diccionario histórico [en línea], disponible en: http://web.frl.es/CNDHE, [consultado el: 03/02/2020].

Clavijero, Francisco Javier (1780), Historia Antigua de México, México D. F., Porrúa.

Clemente, César [trad.] (1606), Historia de los milagros de nuestra Señora de Monteagudo de Sichen, Bruselas, Casa de Rogero Velpio.

CORDE = Real Academia Española (2007-), Corpus diacrónico del español. [en línea], disponible en: http://corpus.rae. es/cordenet.html, [consultado el: 20/02/2020].

CORPES = Real Academia Española (2015-), Corpus del español del siglo XXI. [en línea], disponible en: http://web.frl. es/CORPES, [consultado el: 20/02/2020].

Coxe, John Redman (1817), The Philadelphia Medical Dictionary, containing a concise explanation of all the terms used in medicine, surgery, pharmacy, botany, natural history, chemistry, and materia medica, Philadelphia, Published by Thomas Dobson and Son.

CREA = Real Academia Española (2007-), Corpus del español actual. [en línea], disponible en: http://corpus.rae.es/ creanet.html, [consultado el: 20/02/2020].

Cubero Sebastián, Pedro (1680), Breue relacion de la peregrinacion que ha hecho de la mayor parte del mundo, Madrid, Juan García Infançón.

$D E C H=$ Corominas, Joan y José Antonio Pascual (1980-1991), Diccionario crítico-etimológico castellano e hispánico, Madrid, Gredos.

Domínguez, Ramón Joaquín (1845-1846), Diccionario universal francés-español, Madrid, Establecimiento Léxico-Tipográfico de R. J. Domínguez.

Domínguez, Ramón Joaquín (1846-1847), Diccionario nacional o Gran Diccionario clásico de la lengua española, Madrid, Establecimiento Léxico-Tipográfico de R. J. Domínguez.

Domínguez, Ramón Joaquín (1852), Compendio del Diccionario Nacional de la Lengua Española, II, Madrid, Establecimiento Tipográfico de D. F. de P. Mellado.

Drumen, Juan (1850), Tratado elemental de Patologia médica, I, Madrid, Santacoloma.
Espina y Martínez, Pedro [trad.] (1867): Manual de patología y de clínica médicas, de A. Tardieu, Madrid, Carlos Bailly-Bailliere.

Font Quer, Pío (1962), Plantas Medicinales. El Dioscórides Renovado, Barcelona, Labor.

Gaspar y Roig VV.AA. (1855), Suplemento al Diccionario enciclopédico de la lengua española, I, Madrid, Imprenta y Librería de Gaspar y Roig.

González, Pedro María (1805), Tratado de las enfermedades de la gente de mar en que se exponen sus causas, y los medios de precaverlas, Madrid, Imprenta Real.

Gutiérrez Rodilla, Bertha M. (2012a), "La obra lexicográfica de Manuel Hurtado de Mendoza: sus diccionarios enciclopédicos de medicina", Asclepio, 64 (2), pp. 467-490.

Gutiérrez Rodilla, Bertha M. (2012b), "El Vocabulario terminológico de medicina de Manuel Hurtado de Mendoza", Revista de Filología Española, 92 (2), pp. 249-272.

Gutiérrez Rodilla, Bertha M. (2017), “La preocupación por la lengua y su reflejo en la lexicografía: el caso de los vocabularios españoles de medicina en el siglo XIX y principios del XX", Moenia, 23, pp. 583-602.

Huerta, Jerónimo de [trad.] (1629), Historia natural de Cayo Plinio Segundo, II, Madrid, Juan González.

Hurtado de Mendoza, Manuel (1840), Vocabulario médico-quirúrgico o Diccionario de medicina y cirugía, Madrid, Boix.

Hurtado de Mendoza, Manuel y Celedonio Martínez Caballero (1820-1823), Diccionario de Medicina o cirugía o Suplemento al Diccionario del profesor D. Antonio Ballano, 4 tomos, Madrid, Imprenta de Brugada.

Levi, M. Giussepe (1831-1840), Dizionario classico di medicina interna ed esterna, Venezia, Antonelli.

Mapa de diccionarios - Real Academia Española (2013-), Mapa de diccionarios académicos, [en línea], disponible en: https://apps2.rae.es/ntllet/SrvltGUILoginNtlletPub, [consultado el 20/02/2020].

Martínez Llopis, Manuel (1961), Alimentos y nutrición, Madrid, AULA.

Montenegro, Pedro (1710), Materia médica misionera, Buenos Aires, RBNBA.

NDHE = Instituto de Investigación Rafael Lapesa de la Real Academia Española (2013-), Nuevo diccionario histórico del español, [en línea], disponible en: http://web.frl.es/DH, [consultado el: 20/02/2020].

NTLLE = Real Academia Española (2008-), Nuevo tesoro lexicográfico de la lengua española, [en línea], disponible en: http://ntlle.rae.es/ntlle/SrvltGUILoginNtlle, [consultado el 20/02/2020].

$O L D=$ Glare, Peter G. W. (2012 [1968]), Oxford Latin Dictionary, 2 a ed., Oxford, Clarendon Press.

Olivas Weston, Rosario (1996), La cocina en el virreinato del Perú, Lima, Escuela Profesional de Turismo y Hoteleria / Universidad de San Martín de Porres.

Ortiz, Fernando (1963), Contrapunteo cubano del tabaco y el azúcar, Caracas, Ayacucho. 
Piñera y Siles, Bartholomé [trad.] (1789-1792), Elementos de medicina práctica, de G. Cullen, II,- IV, Madrid, Imprenta de Benito Cano.

Piñera y Siles, Bartholomé [trad.] (1790), Tratado teórico y práctico de las úlceras ó llagas, precedido de un ensayo sobre la direccion y curacion chirúrgica de la inflamacion, supuracion y gangrena; y terminado con una Disertacion acerca de los tumores blancos de las articulaciones, por el célebre Benjamin Bell, Madrid, Imprenta de don Benito Cano.

Rancé, Juan (1773), Tratado theorico-practico de la Materia medica, parte interna, II, Barcelona, Francisco Suriá y Burgada.

Real Academia Nacional de Medicina (2012), Diccionario de términos médicos, Madrid, Editorial Médica Panamericana.

Rodríguez Navas, Manuel (1918), Diccionario general y técnico hispano-americano, Madrid, Cultura Hispanoamericana.

Salvá, Vicente (1879), Suplemento al Nuevo diccionario de la lengua castellana, Paris, Garnier.

Santamaría, Francisco J. (1942), Diccionario general de americanismos, Méjico, Editorial Pedro Robredo.
Sanz y Muñoz, Ángel (1811-1820), Compendio de Medicina práctica arreglado á las explicaciones del doctor don Félix Miquel, I-III, Valencia, Imprenta de Estevan.

Silva y Figueroa, García de (c1618), Comentarios, Madrid, Sociedad de bibliófilos españoles.

Terreros $=$ Terreros y Pando, Esteban (1786-93), Diccionario castellano con las voces de ciencias y artes, Madrid, Viuda de Ibarra, Hijos y Compañía.

$T L F=$ Imbs, Paul y B. Quemada [dirs.] (1971-1994), Trésor de la langue française: Dictionnaire de la langue du XIXe et du XXe siècle (1789-1960), Paris, Gallimard.

VV.AA. (1848), De la pelagra y mal de la rosa de Asturias. Monografía en que se describen estas enfermedades y se responde a las preguntas hechas por la Academia de París, Madrid, Imprenta del Colegio de sordo-mudos y ciegos.

Zerolo, Elías; Toro, Miguel y Emiliano Isaza (1895), Diccionario enciclopédico de la lengua castellana, Paris, Garnier. 